\title{
III' COLLOQUE DE CYTOGÉNÉTIQUE DES ANIMAUX DOMESTIQUES
}

\author{
3 I MAI - 2 JUIN I977
}

C.N.R.Z., JOUY-EN-JOSAS

\section{Résumé des communications libres}

\section{Étude des variations du chromosome $Y$ dans quatre races bovines italiennes}

\author{
Annamaria de GIOVANNI $(*)$ et E. P. CRIBIU (**)
}

(*) Università degli Studi di Milano, Facoltà di Agravia, istituto di Zootecnia Generale: via Celovia 2, 20I33 Milano, Italie

(**) Labovatoive de cytogénétique, U.N.C.E.I.A.-I.N.R.A., Centre national de Recherches zootechniques, $7835^{\circ}$ Jouy-en-Josas, France

Une étude biométrique des variations du chromosome $\mathrm{Y}$ a été entreprise chez Bos taurus $L$. Il a été considéré 84 taureaux appartenant à 4 races italiennes en voie de disparition : Chianina, Modenese, Rendena et Romagnole.

Les résultats font apparaître des différences interraciales hautement significatives de la taille du gonosome $Y$ chez ces quatre races. Le plus grand étant parmi la Rendena et la Modenese et le plus petit chez la Chianina et la Romagnole. 